\title{
Extensive Arterial and Venous Thromboses as the Initial Presentation of Polycythemia Vera
}

Jessica Nathan MD, MSc, Paxton Bach MD, MSc, ABIM, FRCPC, Jake Onrot MD, FRCPC

\author{
About the Authors \\ Jessica Nathan MD, MSc, is with the Department of Medicine, University of British Columbia, Vancouver, BC. \\ Paxton Bach MD, MSc, ABIM, FRCPC, is with the Department of Medicine, St. Paul's Hospital, Vancouver, BC. \\ Jake Onrot MD, FRCPC, is with the Department of Medicine, University of British Columbia, Vancouver, BC and the Department of \\ Medicine, St. Paul's Hospital, Vancouver, BC. \\ Author for correspondence: Jake Onrot, jakeonrot@mac.com \\ Submitted: August 15, 2018. Accepted: October 3, 2018. Published: November 19, 2019.
}

\begin{abstract}
We present here the case of an 81-year-old female with a history of giant cell arteritis whose presenting complaint was nonspecific lower abdominal pain. Her symptoms had been previously unresponsive to antibiotics for presumed diverticulitis, as well as escalating doses of empiric steroids for possible vasculitis. She underwent a computed tomography angiogram, which revealed massive and widespread arterial and venous thromboses. No clear explanation for her hypercoagulable state was found after initial investigations. In the hospital her hemoglobin climbed, peaking at $170 \mathrm{~g} / \mathrm{L}$, with an associated neutrophilia, and a myeloproliferative neoplasm (MPN) was considered. Bone marrow biopsy was consistent with an MPN and the patient was $J A K 2$ positive, leading to a diagnosis of polycythemia vera (PV). We review the differential diagnosis of concomitant arterial and venous thromboembolic events, as well as a discussion of thrombotic events in PV.
\end{abstract}

\section{RESUME}

Nous présentons ici le cas d'une femme de 81 ans ayant des antécédents d’artérite à cellules géantes dont la plainte présentée était une douleur non spécifique au bas-ventre. Ses symptômes étaient auparavant insensibles aux antibiotiques pour une diverticulite présumée, ainsi quà des doses croissantes de stéroïdes empiriques pour une vascularite possible. Elle a subi un angiogramme par tomodensitométrie qui a révélé des thromboses artérielles et veineuses massives et étendues. Aucune explication claire de son état d'hypercoagulation n’a été trouvée après les premières investigations. À l'hôpital, son taux d'hémoglobine a grimpé, culminant à $170 \mathrm{~g} / \mathrm{L}$, avec une neutrophilie associée, et un néoplasme myéloprolifératif (NPP) a été envisagé. La biopsie de la moelle osseuse correspondait à un NPP et le patient était positif à JAK2, ce qui a mené à un diagnostic de polycythémie vera (PV). Nous passons en revue le diagnostic différentiel des événements thromboemboliques artériels et veineux concomitants, ainsi qu'une discussion sur les événements thrombotiques dans le PV. 


\section{Case Presentation}

An 81-year-old woman was transferred to our tertiary care center for further work up of abdominal pain of unknown origin. The patient had a history of hypertension, type 2 diabetes, hypothyroidism, remote transient ischemic attack (TIA), and chronic kidney disease (baseline creatinine of $125 \mu \mathrm{mol} / \mathrm{L}$ ). She was followed by a nephrologist who had arranged a renal biopsy in the preceding year to investigate a gradual decline in her renal function. The biopsy had revealed "thrombotic microangiopathy," which at the time had been attributed to hypertensive nephropathy. Ten years previously, because of temporal headaches and constitutional symptoms, she had been diagnosed with giant cell arteritis (GCA) and treated successfully with steroids. No biopsy was done at that time. She remained well and off steroids for many years.

Six months before admission, she noted symptoms of fatigue, loss of appetite and parietal headache. A temporal artery biopsy was performed and was negative. Steroids were initiated empirically for a supposed relapse of GCA, with a subsequent taper. Despite treatment, her symptoms did not improve, and her C-reactive protein level continued to climb to a value of 72 $\mathrm{mg} / \mathrm{L}$ (baseline value $3 \mathrm{mg} / \mathrm{L}$ ).

One month before admission, the patient developed nausea, vomiting, weight loss and left lower quadrant crampy abdominal pain. Her abdominal symptoms worsened despite several rounds of outpatient antibiotics for presumed diverticulitis. Flexible sigmoidoscopy was negative for colitis. Her prednisone dose was increased from $20 \mathrm{mg}$ to $50 \mathrm{mg}$ daily due to concern that the underlying cause of her abdominal pain was vasculitis, but again no clinical improvement was seen. Given her lack of response, she was admitted to the referring hospital for further work up. Exam at that time was significant only for diffuse abdominal tenderness. Routine blood work revealed hemoglobin of $148 \mathrm{~g} / \mathrm{L}$, hematocrit 0.44 , platelets $171 \times 10^{9} / \mathrm{L}$, and leukocytosis $(24 \times$ $\left.10^{9} / \mathrm{L}\right)$ with a persistent neutrophilia $\left(16.6 \times 10^{9} / \mathrm{L}\right)$, presumed secondary to steroids and/or possible infection. An abdominal non-contrast computed tomography (CT) scan was performed, with contrast being avoided given concerns over her renal function (creatinine of $132 \mu \mathrm{mol} / \mathrm{L}$ ). CT did not reveal the cause of her ongoing abdominal pain, therefore she was referred to our centre.

Upon transfer, she underwent a CT angiogram, which revealed extensive intra-abdominal arterial and venous thromboses. These included a $6 \mathrm{~cm}$ clot in the mid-aorta, as well as clots in the celiac axis, hepatic artery, splenic artery, superior mesenteric artery, bilateral iliac arteries, and extensive bilateral pulmonary emboli (Figure 1). Heparin was initiated. She was not a candidate for thrombolysis or surgical thrombectomy given the timeline of her symptoms. An echocardiogram did not reveal a cardioembolic source. Further imaging of her chest and head and evaluation of tumour markers (CEA, CA 19-9 and CA125) were negative for signs of an underlying solid malignancy. Lupus anticoagulant, anticardiolipin and beta-2 glycoprotein I antibodies were negative. Heparin-induced thrombocytopenia (HIT) assay was negative. A peripheral smear revealed microcytic and hypochromic red cells, platelets with occasional large hypogranular forms, marked leftward shift and no circulating blasts. Fibrinogen was $4.9 \mathrm{~g} / \mathrm{L}$, with no other signs of disseminated intravascular coagulation (DIC). Protein electrophoresis showed a normal pattern.

Serial hemoglobin levels following her admission to the hospital subsequently began rising and peaked at $170 \mathrm{~g} / \mathrm{L}$. Given the elevated hemoglobin level, persistent neutrophilia, and absence of other thrombotic diseases found, a myeloproliferative neoplasm (MPN) was considered. A bone marrow biopsy showed features consistent with a diagnosis of polycythemia vera (PV) including panmyelosis and megakaryocytic clustering with occasional large hyperlobated forms. Serum erythropoietin level was 8.8 $\mathrm{mU} / \mathrm{mL}$ (normal range $3.3-16.6 \mathrm{mU} / \mathrm{mL}$ ). Ultimately, she was found to be positive for the JAK2 mutation, and fluorescence in situ hybridization (FISH) analysis did not reveal a $B C R / A B L$ fusion gene. PV was diagnosed. The patient underwent several phlebotomies in hospital and was initiated on hydroxyurea 500 mg twice a day, given her age over 60 years and the occurrence of a major thrombotic event, classifying her as high risk for further thrombotic complications ${ }^{1}$. Hemoglobin fell to $127 \mathrm{~g} / \mathrm{L}$, hematocrit 0.48 , and white blood cell $15.7 \times 10^{9} / \mathrm{L}$ with treatment. She was eventually transitioned to warfarin from heparin. She was not treated with aspirin as she had a previous allergy and was unwilling to undergo desensitization. Symptomatically she was doing well before discharge with follow-up imaging of her clot burden planned as an outpatient.

\section{Discussion}

Hypercoagulable states should be suspected in patients with synchronous venous and arterial clots, thrombosis at a young age or those that occur in unusual locations, such as involving the mesenteric vasculature. There is a relatively limited differential diagnosis of patients presenting with both arterial and venous thromboembolic events (Table 1). These include HIT, antiphospholipid antibody syndrome (APS), paroxysmal nocturnal hemoglobinuria (PNH), and MPNs. In addition, hyperviscosity states as well as prothrombotic states (as seen in thrombotic thrombocytopenic purpura (TTP)/hemolytic uremic syndrome (HUS) and DIC) can lead to both venous and arterial microthrombi. Lastly, Trousseau's syndrome (unexplained thrombotic events that precede or accompany the diagnosis of an occult malignancy) is predominantly characterized by venous thromboembolic events, but arterial thrombosis secondary to the underlying hypercoagulable state have been reported. In 
general, venous thrombosis is more common than arterial events in all of the above disease states, and interventions are usually aimed at treating the underlying etiology. The presence of a large mural thrombus of the aorta is an impressive feature of this case and a relatively rare finding in the absence of aneurysm or atherosclerosis. Underlying pathologies associated with aortic mural thrombus include the above mentioned hypercoagulable states and have also been found to be associated with aortitis secondary to vasculitis ${ }^{2}$.

$\mathrm{PV}$ is a clonal hematopoietic stem cell disease under the broader classification of $\mathrm{MPNs}^{3}$. The diagnostic criteria include hemoglobin greater than $165 \mathrm{~g} / \mathrm{L}$ in men or $160 \mathrm{~g} / \mathrm{L}$ in women, hematocrit greater than $49 \%$ in men or $48 \%$ in women, or increased red cell mass (25\% above mean normal predicted value). Bone marrow biopsy typically shows hypercellularity for age with trilineage growth (panmyelosis) including prominent erythroid, granulocytic, and megakaryocytic proliferation with pleomorphic, mature megakaryocytes. The JAK2 (V617F) gene mutation is seen in approximately $96 \%$ of patients, with the JAK2 exon 12 mutation only seen in $4 \%$ of patients. ${ }^{4}$ The occurrence of thrombotic complications is a significant feature of MPNs, and is often the initial event leading to diagnosis. The annual incidence of thromboembolic events in MPNs ranges from 1-10\%, depending on the type of MPN, with approximately two-thirds of events being arterial and the remaining one-third venous. ${ }^{5} \mathrm{~A}$ large epidemiological study found that baseline leukocytosis was an independent risk factor specifically for arterial thrombosis ${ }^{6}$. In one large retrospective study of 1213 patients, $41 \%$ of patients with PV had a thrombotic event with a median follow up of 6.1 years, with $64 \%$ of vascular events occurring at presentation or before diagnosis. Interestingly, the majority of the thrombotic events occurred in the 2 years preceding diagnosis, ${ }^{7}$ making it important to consider underlying MPNs in patients presenting with arterial thromboses, such as in this case. During follow up, the incidence of thrombosis was 3.4\% per year with an overall mortality of 2.9 per 100 patient-years. ${ }^{7}$ Despite ongoing investigations into newer treatment options, there remains no cure for PV, with management aimed at risk reduction of lifethreatening thrombotic events.

Treatment of PV includes phlebotomy, with a hematocrit target of less than $45 \%$, as well as once-daily aspirin. ${ }^{1}$ Patients with high risk factors for further thrombotic complications (age $>60$ years, history of thrombosis) are initiated on cytoreductive therapy with hydroxyurea. Systemic anticoagulation is added in patients with a history of venous thrombosis. While low molecular weight heparin is superior to vitamin $\mathrm{K}$ antagonists in malignancy-associated venous thrombosis, ${ }^{8}$ it remains unclear if these benefits extend to patients with MPNs. Therefore, systemic anticoagulation with vitamin $\mathrm{K}$ antagonists is generally recommended in these patients, as there are no trials to date assessing the efficacy of direct oral anticoagulants in patients with MPNs. Twice daily aspirin can be considered in patients with a history of arterial thrombosis according to some experts, however, this is not widespread practice as of yet. ${ }^{1}$ Hematology consultation should be considered in these patients for longterm management.

In summary, we present a case of PV presenting with extensive arterial and venous thrombosis before significant increases in
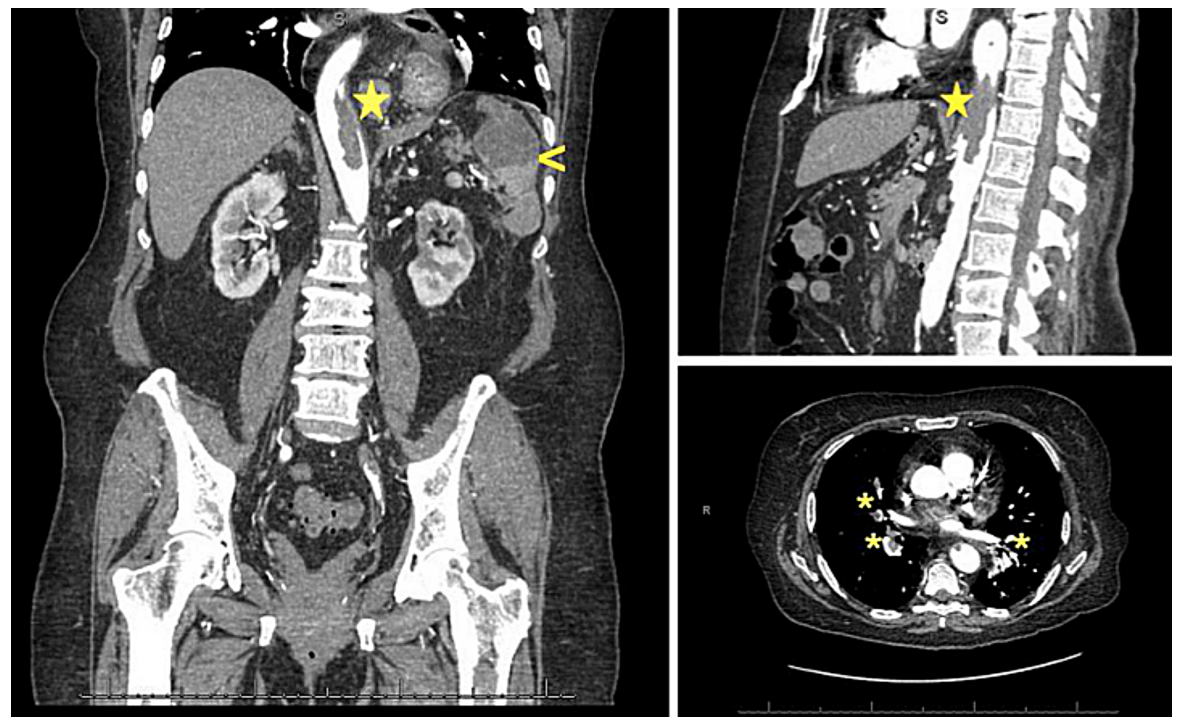

Figure 1. Computed tomography angiogram, showing extensive intra-abdominal arterial and venous thromboses, including a $6 \mathrm{~cm}$ clot in the mid-aorta (star), as well as the hepatic artery, splenic artery with splenic infarction $(<)$, bilateral iliac arteries, and extensive bilateral pulmonary emboli $\left(^{*}\right)$. 
Table 1. Differential Diagnosis of Both Arterial and Venous Thrombosis and Suggested Investigations

\begin{tabular}{|c|c|}
\hline Differential Diagnosis & Diagnostic Approaches \\
\hline Heparin-induced thrombocytopenia (HIT) & Heparin-PF4 antibody enzyme-linked immunosorbent assay (ELISA) \\
\hline Antiphospholipid antibody syndrome (APS) & $\begin{array}{l}\text { Lupus anticoagulant } \\
\text { Anticardiolipin antibodies (IgM and IgG) } \\
\text { Beta-2 glycoprotein I antibodies (IgM and lgG) }\end{array}$ \\
\hline Myeloproliferative neoplasms (MPNs) & $\begin{array}{l}\text { Complete blood count with differential } \\
\text { Serum erythropoietin } \\
J A K 2, C A L R, M P L \text { mutations } \\
B C R / A B L \text { fluorescence in situ hybridization (FISH) } \\
\text { Bone marrow biopsy }\end{array}$ \\
\hline Paroxysmal nocturnal hemoglobinuria (PNH) & $\begin{array}{l}\text { Flow cytometry for CD55 and CD59 } \\
\text { Complement lysis sensitivity test }\end{array}$ \\
\hline $\begin{array}{l}\text { Thrombotic thrombocytopenic purpura (TTP)/hemolytic uremic } \\
\text { syndrome (HUS) }\end{array}$ & $\begin{array}{l}\text { Complete blood count with peripheral smear (schistocytes) } \\
\text { Lactate dehydrogenase (LDH) } \\
\text { Unconjugated bilirubin } \\
\text { Haptoglobin } \\
\text { Urinalysis } \\
\text { ADAMTS13 level and inhibitor (IgG) }\end{array}$ \\
\hline Disseminated intravascular coagulopathy (DIC) & $\begin{array}{l}\text { Prothrombin time (PT) } \\
\text { Partial thromboplastin time (PTT) } \\
\text { Fibrinogen } \\
\text { Complete blood count with peripheral smear } \\
\text { D-dimer }\end{array}$ \\
\hline Waldenstrom's Macroglobulinemia & $\begin{array}{l}\text { Serum protein electrophoresis (IgM) } \\
\text { Bone marrow biopsy or aspiration (MYD88 mutation) } \\
\text { CT scan (lymphadenopathy) }\end{array}$ \\
\hline Sickle cell disease & $\begin{array}{l}\text { Complete blood count with peripheral smear } \\
\text { Hemoglobin electrophoresis }\end{array}$ \\
\hline Cryoglobulinemia & Serum cryoglobulins \\
\hline Dysfibrinogenemia & $\begin{array}{l}\text { Thrombin time } \\
\text { Reptilase time } \\
\text { Fibrinogen clotting activity-antigen ratio }\end{array}$ \\
\hline Trousseau's syndrome & $\begin{array}{l}\text { Age-appropriate malignancy screening } \\
\text { Consider computed tomography of chest, abdomen and pelvis } \\
\text { Consider endoscopy }\end{array}$ \\
\hline
\end{tabular}

hemoglobin levels. This case highlights the pitfalls of anchoring bias, with both continuation of treatment for presumed vasculitis despite no improvement with steroids, and treatment for diverticulitis despite no correlation on imaging and the potential morbidity associated with performing a sigmoidoscopy in this setting. Also, the decision to avoid contrast in a patient with a GFR $<45 \mathrm{~mL} / \mathrm{min}$ led to a delay in diagnosis. ${ }^{9}$ In the case of our patient, the benefit outweighed the risks as her diagnosis was 
unrecognized until a CT angiogram was performed showing widespread thromboses. In retrospect, her symptoms of a vasculitis 'relapse' were likely related to her underlying PV. Besides, the previous history of TIA and thrombotic microangiopathy seen on renal biopsy may very well have been early sequelae of her underlying hypercoagulable state. In this clinical setting, in the absence of other causes of both arterial and venous thrombosis, a diagnosis of MPN must be considered, especially given the relative ease and availability of testing for genetic mutations such as JAK2.

\section{References}

1. Tefferi A, Vannucchi, A, Barbui, T. Polycythemia vera treatment algorithm 2018. Blood Cancer J 2018;8(1):3.

2. Tsilimparis N, Hanack, U, Pisimisis, G, et al. Thrombus in the nonaneurysmal, non-atherosclerotic descending thoracic aorta - an unusual source of arterial embolism. Eur J Vasc Endovasc Surg 2011;41(4):450-57.
3. Arber DA, Orazi A, Hasserjian R, et al. The 2016 revision to the World Health Organization classification of myeloid neoplasms and acute leukemia. Blood 2016; 127(20):2391-405.

4. Rumi E, Cazzola M. Diagnosis, risk stratification, and response evaluation in classical myeloproliferative neoplasms. Blood 2017;129(6):680-92.

5. Casini A, Fontana P, Lecompte TP. Thrombotic complications of myeloproliferative neoplasms: risk assessment and risk-guided management. J Thromb Haemost 2013;11(7):1215-27.

6. Landolfi R, Di Gennaro L, Barbui T, et al. European Collaboration on Low-Dose Aspirin in Polycythemia Vera (ECLAP). Leukocytosis as a major thrombotic risk factor in patients with polycythemia vera. Blood 2007;109(6):2446-52.

7. Gruppo Italiano Studio Policitemia. Polycythemia vera: the natural history of 1213 patients followed for 20 years. Ann Intern Med 1995;123:656-64.

8. Lee A, Levine M, Baker, R, et al. Low-molecular-weight heparin versus a coumarin for the prevention of recurrent venous thromboembolism in patients with cancer. N Eng J Med 2003;349:146-53.

9. Owen, R, Hiremath, S, Myers, A, et al. Canadian Association of Radiologists Consensus Guidelines for the Prevention of Contrast-Induced Nephropathy: Update 2012 2012;65(2):95-105. 